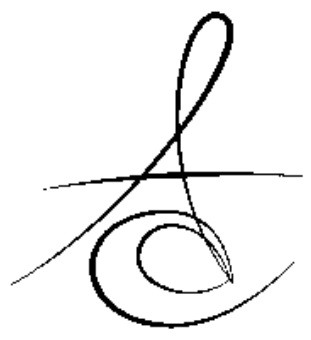

\title{
LATERAL PERİODONTAL KİST: NADİR BİR OLGU SUNUMU
}

LATERAL PERIODONTAL CYST: A RARE CASE REPORT

\author{
Yrd. Doç. Dr. Onur ŞAHİN*
}

Uzm.Dt. Onur ODABAŞI ${ }^{* *}$

Dr. Dt. Mehmet Emin TOPRAK ${ }^{* * *}$

\author{
Makale Kodu/Article code: 2786 \\ Makale Gönderilme tarihi: 12.04 .2016 \\ Kabul Tarihi: 17.06 .2016
}

öz

Lateral periodontal kist (LPK), çoğunlukla mandibular kanin ve premolar bölgede, dişlerin lateral yüzeylerinde lokalize olan ve nadir olarak görülen gelişimsel odontojenik bir kist türüdür. Patolojisi tam olarak bilinmemekle beraber mine epiteli, malessez hücre kalıntıları veya dental lamina artıklarından köken aldığı düşünülmektedir. Sıklıkla asemptomatiktir ve rutin radyolojik muayene sonucunda tespit edilebilmektedir. Radyografik görüntüsü genellikle iyi sınırlı, yuvarlak veya oval radyolüsent lezyon şeklindedir. Lateral periodontal kistin ayırıcı tanısı aynı bölgede görülebilen radiküler kist, glandular odontojenik kist ve odontojenik keratokistik tümör ile yapılmalıdır. $\mathrm{Bu}$ olgu sunumunda 40 yaşında erkek bireyde tespit edilen, mandibular premolar bölgede lokalize lateral periodontal kistin tedavisi sunulmaktadır.

Anahtar Kelimeler: Lateral periodontal kist, odontojenik kist, mandibula

\section{ABSTRACT}

Lateral periodontal cyst (LPC) is an uncommon developmental odontogenic cyst, located commonly on the lateral aspect of roots of mandibular canine and premolar. LPC lesion is now believed to originate from enamel epithelium, rests of Malassez and dental lamina remains. It is often asymptomatic and can be observed during routine radiological examinations. Radiographic image is usually in well-defined, round or oval-shaped radiolucent lesion form. The differantial diagnosis of the lateral periodontal cyst should be taken consideration from radicular cyst, glandular odontogenic cysts and odontogenic keratocyst tumors be able to seen in the same region. In the present study, treatment of lateral periodontal cyst localized around the mandibular premolar region be able to observed on 40-year-old man is presented.

Keywords: Lateral periodontal cyst, odontogenic cyst, mandible

\section{GİRìs}

Kistler iç yüzeyi epitel ile döşeli bir bağ dokusu kapsülü ile çevrili olan, içi sıvı veya yarı sıvı materyalle dolu patolojik boşluklardır. Kistler, çenelerdeki kronik şişliklerin en yaygın sebeplerindendir. Epiteli olmayan ve radyolojik olarak kist benzeri görüntü veren lezyonlarsa psödokist adını alır. ${ }^{1}$

Kistler epiteli olan kistler ve epitelsiz kistler olarak ikiye ayrılırlar. Epitel içerikli kistler de odontojenik ve non-odontojenik kistler olarak ikiye ayrılırlar. Lateral periodontal kist (LPK) ise odontojenik kistlerin dental laminadan köken alan gelişimsel kistler grubuna dahildir. ${ }^{2,3}$ LPK'ler her çenelerde daha çok kanin/ premolar bölgesinde lokalize olurken \%80'inden fazlası da mandibulada görülmektedir. ${ }^{4}$ Çene kemiklerinde oluşan tüm kistler içerisinde $\% 0,7$, odontojenik kistler içerisinde ise $\% 0,4$ oranında nadir görülen bir kisttir. ${ }^{5}$

Gelişimsel, non-keratinize, odontojenik bir kist olan LPK; ilgili diş sekonder olarak enfekte olmadıkça vital bir diş kökünün lateral yüzeyi boyunca periodonsiyum içerisindeki epitel artıklarının proliferasyonu sonucu meydana gelir. 20-90 yaş aralığında rastlanılan bu kistin ortalama görülme yaşı 50'dir. Cinsiyet ayrımı göstermez, çoğunlukla mandibulada kanin-premolar ve daha az sıklıkla maksiller anterior bölgede gözlenir ve genellikle asemptomatiktir. ${ }^{6,7}$ 
LPK vital bir dişin lateral periodontal bölgesinden gelişir ve karakteristik histolojik özelliklere sahiptir. Diş etinin bukkalinde fluktuasyon veren bir şişlik ve renk değişikliğine sebep olabilir. Ancak genel olarak asemptomatiktir ve rutin radyolojik muayene esnasında fark edilir. Radyografide uniloküler, yuvarlak, oval ya da gözyaşı damlası şeklinde iyi sınırlı, interradiküler radyolüsent lezyon olarak gözlenir ve genellikle $1 \mathrm{~cm}$ 'den küçüktür. ${ }^{8}$

Bu olgu raporunda, 33 ve 34 numaralı dişler arasında şişlik şikayeti ile kliniğimize başvuran ve periapikal radyografide ilgili dişler arasında iyi sınırlı, radyolüsent görüntü veren ve histopatolojik inceleme sonucunda nadir görülen LPK tanıSı konulan bir olgu sunulmaktadır.

\section{OLGU SUNUMU}

39 yaşında erkek hasta alt çene sol bölgede meydana gelen şişlik; ilgili bölgedeki dişlerde yer değişikliği ve lokalize baskı şikayetleri ile kliniğimize başvurmuştur. Ekstraoral muayene esnasında herhangi bir patolojik bulguya rastlanılmamıştır. İntraoral muayenede sol mandibular kanin ve 1 . premolar numaralı dişlerin köklerinin arasındaki alanda alveoler kemiğin devamlıığının olmadığı, dişetinin o bölgede mavimsi bir renk taşıdığı ve palpasyonda fluktuan olduğu gözlenmiştir (Resim 1). Radyografik muayenede sol mandibular kanin ve 1 . premolar dişlerin kökleri arasında yuvarlak, yaklaşık $8 \mathrm{~mm}$ büyüklüğünde, radyoopak sınırlı radyolüsent bir alan izlenmiş, yapılan pulpa vitalite testlerinde sol mandibular kanin ve 1. premolar dişlerin vital olduğu ve simetriğindeki aynı dişlerle benzer cevaplar alındığı gözlenmiştir (Resim 2).

Klinik ve radyolojik muayene sonucunda LPK ön tanısıyla lezyonun cerrahi olarak eksizyonu planlanmıştır.

Hastaya cerrahi işlemler öncesinde sol mandibula premolar bölgesine lokal anestezi uygulanmıştır. Lokal anestezilerin kontrolünden sonra dişetlerinden geçen sulkuler insizyon ile lateral ve 1.premolar dişlere rahatlatıcı vertikal insizyonlar uygulanarak tam kalınlık mukoperiostal flep kaldırılmış ve ilgili bölgeye ulaşılmıştır. Lezyonu çevreleyen kortikal kemikte perforasyon olduğu izlenmiştir (Resim 3). İlgili bölgeye tümüyle ulaşabilmek için lezyonun çevresindeki kemik dokusu cerrahi frez yardımıyla kaldırılıp, lezyona komşu bölgedeki dişlerin kökleri korunarak lezyonun enükleas- yonu gerçekleştirilmiş ve flep orijinal konumuna süture edilmiştir (Resim 4). Çıkarılan dokunun histopatolojik değerlendirmeye gönderilmesi sonucu yapılan incelemede lezyonun LPK olduğu saptanmıştır. Operasyondan sonraki 6 aylık takip sürecinde herhangi bir nüks veya patoloji bulgusuna rastlanmamıştır.

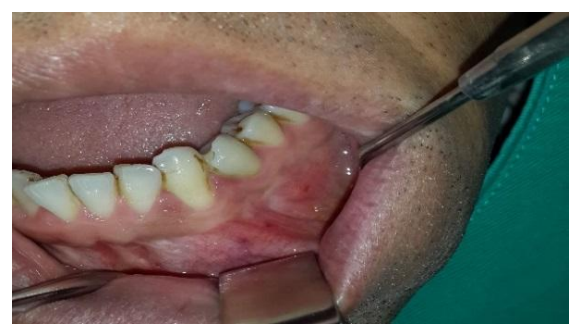

Resim 1. Olgunun ağız içi görünümü.

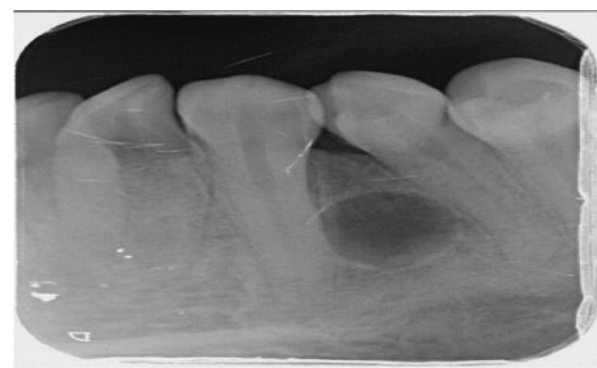

Resim 2. LPK'nin periapikal radyografideki görüntüsü

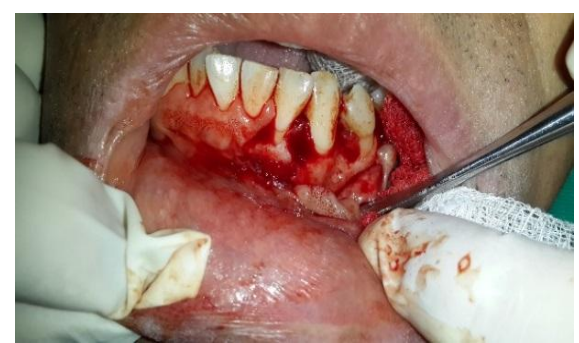

Resim 3. Kortikal kemikteki perferasyon.

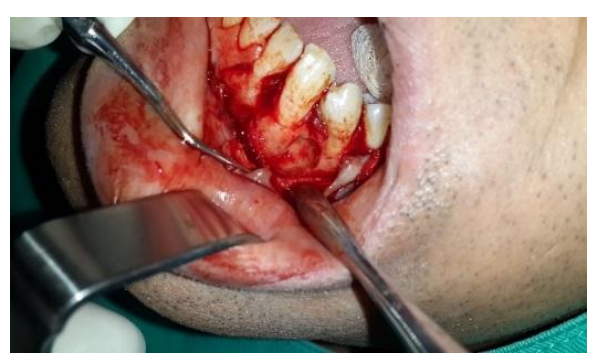

Resim 4. Operasyon sonrası ağı içi görünümü 
Atatürk Üniv. Diş Hek. Fak. Derg.

J Dent Fac Atatürk Uni

Cilt:28, Sayı:1, Yıl: 2018, Sayfa: $88-90$

\section{TARTIŞMA}

LPK'ler dental lamina artıklarından köken alan, sürmüş dişlerin periodontal aralı̆ına yerleşim gösteren lezyonlardır. Histolojik olarak LPK'nin iç yüzeyi çok katı yassı epitelle döşelidir. LPK; sunduğumuz vakada olduğu gibi daha çok alt çenede kanin-premolar dişler bölgesinde görülür. ${ }^{4}$

LPK radyografik olarak kenarları düzgün sklerotik sınırlı radyolusent bir lezyon şekilde görülür. Radyolüsent saha genellikle vital dişin kök yüzeyinin lateralindedir ve çapı çoğunlukla $1 \mathrm{~cm}$ kadardır. ${ }^{8}$ Bununla birlikte kök yüzeyinin lingualinde de yerleşim gösterdiği rapor edilmiştir. ${ }^{9}$

LPK; inflamatuvar ve diğer gelişimsel odontojenik kistlerle, odontojenik tümörlerle karışabilir. Özellikle botryoid odontojenik kist ve yetişkinlerin gingival kisti ile ayırıc tanısı yapılmalıdır. ${ }^{10}$ Botryoid odontojenik kist lateral periodontal kistin multiloküler varyantıdır. Yaş ve bölge dağılımları benzerdir. Radyografik olarak LPK'den daha geniş olabilir ve genellikle multiloküler yapı izlenir. Ayırıcı tanıda multiloküler oluşu önemli bir ayrıntıdır. Mikroskobik olarak ince fibröz septumlar ile bölmelere ayrılmıştır. Kistin iç yüzeyi kist kavitesine doğru sporadik tomurcuk benzeri, nodüler veya plak benzeri proliferasyonların uzandığı ve açık renkli, glikojen dolu hücreler içeren yassılaşmış nonkeratinize çok katı yassı epitel ile döşelidir. ${ }^{10}$ Vakamızda lezyonun uniloküler olması, komşu dişlerin vital olması ve maligniteyi düşündürecek bir bulgu olmamasından dolayı diğer pato- lojilerle ayıııc tanısı yapılmışıı. Cerrahi olarak alınan lezyonun histopatolojik değerlendirilmesi sonucu LPK tanısı kesinleşmiştir.

LPK olgularında dişler vitaldir ve özellikle lezyonun apikale yakın konumlandığı vakalarda ayırıı tanısı doğru yapılmaz ise komşu dişlere gereksiz kanal tedavisi uygulaması veya ilgili dişlerin çekimi ile sonuçlanabilmektedir. Hekim lateral periodontal kisti andıran klinik ve radyolojik görüntüler konusunda bilgili olmalı, ayırıcı tanıyı yapabilmeli ve tedavi seçeneklerini bu bilgiler doğrultusunda şekillendirebimelidir.

Onur Şahin, ORCID ID: 0000-0001-7816-1443 Onur Odabaşı, ORCID ID : 0000-0001-7771-048X Mehmet Emin Toprak, ORCID ID: 000-0003-4281-5913
ŞAHİN, ODABAŞI, TOPRAK

\section{KAYNAKLAR}

1. Cawson RA, Odell EW. Cawson's Essentials of Oral Pathology and Oral Medicine 7th ed. London: Churchill Livingstone: 2002. p.102- 121.

2. Cohen DA, Neville BW, Damm DD, White DK. The lateral periodontal cyst. A report of 37 cases. J Periodontol 1984;55:230-4

3. Soares de Lima AA, Naval Machado MÂA, Braga AM, De Souza MH. Lateral periodontal cyst: Aetiology, diagnosis and clinical significance. A review and report of case. Rev Clín Pesqui Odontol 2005; $1: 55-9$.

4. Altini $M$, Shear $M$. The lateral periodontal cyst: an update. J Oral Pathol Med 1992;21:245-50

5. de Andrade $M$, Silva AP, de Moraes Ramos-Perez FM, Silva-Sousa YT, da Cruz Perez DE. Lateral periodontal cyst: report of case and review of the literature. Oral Maxillofac Surg 2012;16:83-7.

6. White SC, Pharoah JM. Oral Radiology- Principles and Interpretation. 6th ed; China; Elsevier: 2009. p.355-6.

7. Langlais RC, Miller SC, Nield-Gehric JS. Colour Atlas of Common Oral Disease. 4th ed; USA; Walters Kluwer: 2009. p 72.

8. Angelopoulou E, Angelopoulos AP. Lateral periodontal cyst. Review of the literature and report of a case. J Periodontol 1990;61:126-31.

9. Dağıstan S, Bayrakdar İŞ. Lateral periodontal kist: vaka raporu. Atatürk Üniv Diş Hek Fak Derg 2014; 8:23-26.

10.Méndez P, Junquera L, Gallego L, Baladrón J. Botryoid odontogenic cyst: clinical and pathological analysis in relation to recurrence. Med Oral Patol Oral Cir Bucal 2007;12:594- 98.

\author{
Yazışma Adresi \\ Uzm.Dt. Onur ODABASI \\ Gazi Üniversitesi Diş Hekimliği Fakültesi \\ Ağız Diş ve Çene Cerrahisi AD \\ Bişkek Cd.(8.Cd.) 82.Sk. No:4 06510 \\ Emek - ANKARA \\ TIf: 5370234350 \\ onurodabasi88@gmail.com
}

